\title{
Research Paper: Correlation of INECO Frontal Screening With Verbal Fluency Tasks and MMSE in Persian Healthy Population
}

\author{
Fatemeh Satarian' $^{1}$ (D, Azar Mehri ${ }^{1 *}$ (D), Shohreh Jalaie ${ }^{2}$
}

1. Department of Speech Therapy, School of Rehabilitation, Tehran University of Medical Sciences, Tehran, Iran

2. Department of Physiotherapy, School of Rehabilitation, Tehran University of Medical Sciences, Tehran, Iran.

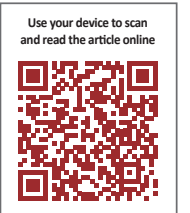

crtation: Satarian F, Mehri A, Jalaie Sh. Correlation of INECO Frontal Screening With Verbal Fluency Tasks and MMSE in Persian Healthy Population. Journal of Modern Rehabilitation. 2018; 12(1):21-30. http://dx.doi.org/10.32598/jmr.12.1.21

http://dx.doi.org/10.32598/jmr.12.1.21

Funding: See Page 28

(c) Copyright: The Author(s)

Article info:

Received: 25 Jun 2017

Accepted: 12 Oct 2017

Available Online: 01 Jan 2018

\section{Keywords:}

Neuropsychology,

Executive function, Verbal

fluency, Mini-Mental State

Examination(MMSE), Validity

\section{A B STRACT}

Introduction: INECO Frontal Screening (IFS) is a brief sensitive screening tool able to detect executive dysfunctions. IFS-P is the Persian version of IFS. This study aimed to investigate and analyze the correlation between IFS-P test with cognitive and executive function tests. We seek to investigate whether these tests can replace each other.

Materials and Methods: In this cross-sectional study, IFS-P was administered to 50 healthy people along with other executive assessments such as phonological verbal fluency (letters A, $\mathrm{S}$ and $\mathrm{F}$ ), semantic verbal fluency (animals, fruits and verbs), and a global cognitive efficiency test (Mini-Mental State Examination [MMSE]). The Spearman coefficient test was used to investigate the correlation between IFS-P and other executive and general cognitive tests.

Results: The obtained results show no significant correlations between the IFS-P and the other cognitive instruments such as MMSE test. However, IFS-P correlates with verbal fluency tasks (semantic and phonological) in healthy people. Specifically, the correlation between IFS-P total score and other tests are as follows: for MMSE, $\mathrm{r}=0.20(\mathrm{P}=0.10)$; for $/ \mathrm{F} / \mathrm{phonological}$ verbal fluency, $\mathrm{r}=0.36(\mathrm{P}=0.00)$; for $/ \mathrm{S} /$ phonological verbal fluency, $\mathrm{r}=0.44(\mathrm{P}=0.00)$; for $/ \mathrm{A} /$ phonological verbal fluency, $\mathrm{r}=0.35(\mathrm{P}=0.00)$; for fruits semantic verbal fluency, $\mathrm{r}=0.30$, $(\mathrm{P}=0.00)$; for animals semantic verbal fluency, $\mathrm{r}=0.38(\mathrm{P}=0.00)$; and for verbs semantic verbal fluency, $\mathrm{r}=0.56,(\mathrm{P}=0.00)$.

Conclusion: IFS-P is a brief, sensitive, and specific tool for the detection of executive dysfunction associated with neurodegenerative diseases. IFS-P correlates with the verbal fluency and does not correlate with the MMSE and cannot be replaced by them. Based on the results, we suggest that all three tests be used together. 


\section{Introduction}

I

NECO Frontal Screening (IFS) is an executive test designed by Torallva et al. in 2009. It is a new brief tool to evaluate executive functions in neurodegenerative diseases. This screening test was meant to determine frontal dysfunction in patients with dementia. In other words, IFS is an executive screening test that assesses several executive processes by using a few tasks. Internal consistency of IFS is very good (Cronbach $\alpha=0.80$ ).

The cut-off score of this test is 25 points. The sensitivity and specificity of the IFS were $96.2 \%$ and $91.5 \%$, respectively in differentiating controls from patients with dementia. The IFS correlates significantly with executive tasks such as verbal fluency tasks [1]. This test has been translated into other languages, including Chilean and Persian. Ihnen et al. translated the Chilean version (IFS-Ch) in 2013 and tested it on 30 healthy persons and 31 patients with dementia and calculated its validity and reliability in this language. Internal consistency of the IFS-Ch is very good (Cronbach $\alpha=0.90$ ). The cut-off score of IFS-Ch is 18 points. The sensitivity of the IFS was $90 \%$, and its specificity was $86 \%$ [2].

Persian version of IFS was adapted and translated by Satarian and associates [3]. This screening test was designed to determine frontal dysfunction in patients with dementia and to discriminate between different types of dementia. It consists of 8 executive function subtests which include motor series (programming), conflicting instructions (interference sensitivity), GO/NO-GO (inhibitory control), digits backward, verbal working memory, spatial working memory, abstraction capacity (proverbs), verbal inhibitory control (Hayling Test) [1]. Total score is calculated by adding all 8 subtests scores; the test has a maximum possible score of 30 points. The administration time is maximum 10 minutes. This test is brief, fast and sensitive to detection of executive dysfunction. Mini-Mental State Examination (MMSE) is a short cognitive screening test that consists of two cognitive and linguistic parts as well as 9 subtests. This test has a total of 30 grades and can identify people with cognitive problems.

Executive functions refer to a set of cognitive behaviors including making decision, planning, self-monitoring, initiation, inhibition, organization [4-7], working memory, problem solving [8], ability to sustain attention, resistance to interference, ability to co-ordinate simultaneous activity, cognitive flexibility, and abil- ity to deal with novelty [9]. we know that executive dysfunction effects daily living activity $[5,6]$. Patients with dementia have problems with executive function. Therefore, the diagnosis of these executive dysfunctions in these patients can help to treat them. So an appropriate screening test can help these patients a lot. There are a lot of various tests and batteries to evaluate executive dysfunctions in adults. Some of these included verbal tasks and some nonverbal tasks, also some tests included both verbal and nonverbal tasks. Among the 26 common and brief screening tests that evaluate executive function, one of the best screening tests with good psychometric data is the IFS test.

Among these tests, only Frontal Assessment Battery (FAB) test has been translated into Persian [10]. Also IFS has recently been translated into Persian [3]. In this study, we studied IFS because of its better psychometric information than FAB and more correlation with other standard tests in the field of executive dysfunction. It should be noted that the Persian version of the test was used in this study. The IFS-P is the Persian version of IFS with the Cronbach $\alpha$ coefficient of 0.67 , the cut-off point of 19.5 , the sensitivity of 0.95 , the specificity of 0.90 and an area under curve of 0.979 [3].

As noted, various tests examine executive functions in healthy individuals and patients. In addition, each test has subtests that sometimes are shared between different tests. It is argued that if these tests evaluate a shared skill and function then they should have correlations. The present study was designed to answer this question. This study aimed to determine the correlation between the components of IFS-P test and other tests in the field of cognition and executive function, as well as to examine how people respond to this test and compare it with other tests. For this purpose, since the IFS test has a linguistic component, among the cognitive screening tests, MMSE [11] test was selected because of its having two parts of language and cognition. Also among the executive function tests, the verbal fluency [12] tasks were selected for their relevance to the language.

\section{Materials and Methods}

This cross-sectional study investigates the relationship between IFS-P and executive tests such as verbal fluency and general cognitive tests such as MMSE. Also the scores of the samples in all three tests were analyzed. Because this study is the first in this topic, we selected and studied 50 persons in pilot form. The study included 50 normal participants aged between 20 and 70 years (an average of 50 years) selected through sample, includ- 
ing 20 men and 30 women. Participants had the ability to read and write and almost to Master in Sciences to enter this study. The participants were selected from public places such as parks, offices and universities. They gave their informed consent to participate in the research. They were also surveyed with a questionnaire and had no history of either neurological or psychological disorder.

The study inclusion criteria were as follows: lacking speech and language problems, having correct reading and writing without visual and auditory problems. The exclusion criteria were individuals' unwillingness to continue the research. The participants' information remains confidential to comply with the ethics principles. After administrating IFS-P test to all participants, they were evaluated with verbal fluency tasks (semantic and phonological fluency) and MMSE [11]. Semantic verbal fluency (specifically animal, fruit and verb) and phonological verbal fluency (specifically F, A and S) were used [12].

The correlation between IFS-P with MMSE, correlation between IFS-P with verbal fluency tasks and correlation between MMSE with verbal fluency tasks were computed. In this regard, mean, median, minimum and maximum obtained scores in the IFS-P and all 8 subtests, in the MMSE and both their linguistic and cognitive parts and verbal fluency tasks were calculated and compared with each other. Because the data were not normally distributed, the correlations were determined by Spearman coefficient. Statistical analyses were performed in SPSS V. 22.

\section{Results}

Table 1 presents demographic data and general cognitive status information of the participants. The IFS-P total score and its subtest scores, verbal fluency tasks scores and MMSE total, cognitive and language parts scores (mean, median, minimum and the maximum) were presented in Table 2 for female and male participants separately.
According of results, the mean IFS-P total score in men is higher than that in women but in the MSSE test, women have a higher score than men. In verbal fluency scores, the highest score belongs to semantic verbal fluency, so semantic verbal fluency scores are better than phonological verbal fluency scores. Because the data were not normally distributed, the Spearman correlation coefficient was used to calculate the correlations among IFS-P and verbal fluency and MMSE. Table 3 presents the results of the correlation between the IFS-P and its subtests with the MMSE test. Table 4 presents the correlation between the IFS-P and its subtests with the verbal fluency tasks. Finally, Table 5 presents the correlation between MMSE and verbal fluency tasks. In Table 5, the MMSE is divided into language and cognitive parts, and the correlation with each part is listed. Each result is explained in the following paragraph.

According to the results, there is no correlation between MMSE total score (both linguistic and cognitive parts) and total score of the IFS-P test, but with respect to some IFS-P subtests (3 subtests) the correlations are seen with the MMSE total score. For example, the first subtest (motor programming) correlates highly with the total score of MMSE $(\mathrm{r}=0.30, \mathrm{P}=0.000)$. Table 3 presents other correlation coefficients which are summarized and categorized. Overall, the number of IFS-P subtests that have significant correlation with MMSE is low, i.e. IFS-P total score with the MMSE total score as well as the score of both parts of the MMSE (cognitive, language) with each other. Therefore, these two tests are not related in healthy people.

The results also show a significant correlation between IFS-P and verbal fluency tasks. The total score of IFS-P test has a significant correlation with all six verbal fluency tasks including semantic verbal fluency and phonological verbal fluency $(\mathrm{P}<0.05)$. The highest correlation between the IFS-P test and the semantic verbal fluency is related to verbs and between the IFS-P test and phonological verbal fluency is related to $/ \mathrm{S} /$.

Table 1. Demographic and general cognitive status information

\begin{tabular}{cc}
\hline Demographic Information & Participants (N=50) \\
\hline Age, Mean (SD), y & $50.20(12.50)$ \\
Gender (M:F) & $20: 30$ \\
Monolingual: bilingual & $35: 15$ \\
\hline
\end{tabular}


Table 2. The IFS-P score, verbal fluency tasks, and MMSE scores

\begin{tabular}{|c|c|c|c|c|c|}
\hline Tests & Gender & Mean (SD) & Median & Min & Max \\
\hline \multirow{3}{*}{ IFS-P } & Female & $24.73(3.19)$ & 24.73 & 29.50 & 15 \\
\hline & Male & $26.4(3.00)$ & 27 & 29 & 16 \\
\hline & Total & $25.4(3.16)$ & 26 & 29.50 & 15 \\
\hline \multirow{3}{*}{$\begin{array}{l}\text { IFS-P } \\
\text { Task } 1\end{array}$} & Female & $3(0.00)$ & 3 & 3 & 3 \\
\hline & Male & $3(0.00)$ & 3 & 3 & 3 \\
\hline & Total & $3(0.00)$ & 3 & 3 & 3 \\
\hline \multirow{3}{*}{$\begin{array}{l}\text { IFS-P } \\
\text { Task } 2\end{array}$} & Female & $2.73(0.58)$ & 3 & 3 & 1 \\
\hline & Male & $2.85(0.36)$ & 3 & 3 & 2 \\
\hline & Total & $2.73(0.58)$ & 3 & 3 & 1 \\
\hline \multirow{3}{*}{$\begin{array}{l}\text { IFS-P } \\
\text { Task } 3\end{array}$} & Female & $2.60(0.56)$ & 3 & 3 & 1 \\
\hline & Male & $2.75(0.40)$ & 3 & 3 & 2 \\
\hline & Total & $2.60(0.56)$ & 3 & 3 & 1 \\
\hline \multirow{3}{*}{$\begin{array}{l}\text { IFS-P } \\
\text { Task } 4\end{array}$} & Female & $3.93(1.36)$ & 4 & 6 & 2 \\
\hline & Male & $4.30(0.97)$ & 4.50 & 6 & 2 \\
\hline & Total & $4(1.21)$ & 4 & 6 & 2 \\
\hline \multirow{3}{*}{$\begin{array}{l}\text { IFS-P } \\
\text { Task } 5\end{array}$} & Female & $1.80(0.48)$ & 2 & 2 & 0 \\
\hline & Male & $1.75(0.63)$ & 2 & 2 & 0 \\
\hline & Total & $1.75(0.53)$ & 2 & 2 & 0 \\
\hline \multirow{3}{*}{$\begin{array}{l}\text { IFS-P } \\
\text { Task } 6\end{array}$} & Female & $3(0.98)$ & 3 & 4 & 1 \\
\hline & Male & $3.3(0.73)$ & 3 & 4 & 2 \\
\hline & Total & $3.10(0.83)$ & 3 & 4 & 1 \\
\hline \multirow{3}{*}{$\begin{array}{l}\text { IFS-P } \\
\text { Task } 7\end{array}$} & Female & $2.68(0.62)$ & 3 & 3 & 0.50 \\
\hline & Male & $2.85(0.28)$ & 3 & 3 & 2 \\
\hline & Total & $2.70(0.50)$ & 3 & 3 & 0.50 \\
\hline \multirow{3}{*}{$\begin{array}{l}\text { IFS-P } \\
\text { Task } 8\end{array}$} & Female & $5(0.96)$ & 5 & 6 & 3 \\
\hline & Male & $5.50(0.82)$ & 6 & 6 & 3 \\
\hline & Total & $5.20(0.96)$ & 5.50 & 6 & 3 \\
\hline \multirow{3}{*}{ MMSE } & Female & $29(1)$ & 29 & 30 & 26 \\
\hline & Male & $28(0.91)$ & 29 & 30 & 27 \\
\hline & Total & $28.90(1)$ & 29 & 30 & 26 \\
\hline \multirow{3}{*}{$\begin{array}{c}\text { MMSE } \\
\text { Cognitive part }\end{array}$} & Female & $20(0.93)$ & 21 & 21 & 18 \\
\hline & Male & $19(0.93)$ & 20 & 21 & 18 \\
\hline & Total & $20(0.93)$ & 20 & 21 & 18 \\
\hline \multirow{3}{*}{$\begin{array}{c}\text { MMSE } \\
\text { Language part }\end{array}$} & Female & $8.80(0.40)$ & 9 & 9 & 8 \\
\hline & Male & $8.80(0.40)$ & 9 & 9 & 8 \\
\hline & Total & $8.80(0.40)$ & 9 & 9 & 8 \\
\hline \multirow{4}{*}{$\begin{array}{l}\text { Verbal fluency } \\
\qquad / F /\end{array}$} & Female & $11(3.20)$ & 10 & 18 & 6 \\
\hline & & 11.34 & & & \\
\hline & Male & (4.13) & 10 & 19 & 4 \\
\hline & Total & 11.34(3.63) & 10 & 19 & 4 \\
\hline \multirow{3}{*}{$\begin{array}{l}\text { Verbal fluency } \\
\qquad / \mathrm{S} /\end{array}$} & Female & $14.64(4.50)$ & 14 & 30 & 8 \\
\hline & Male & $14.10(4.91)$ & 14 & 21 & 5 \\
\hline & Total & $14.42(4.60)$ & 14 & 30 & 5 \\
\hline
\end{tabular}




\begin{tabular}{|c|c|c|c|c|c|}
\hline Tests & Gender & Mean (SD) & Median & Min & Max \\
\hline \multirow{3}{*}{$\begin{array}{c}\text { Verbal fluency } \\
\qquad \text { /A/ }\end{array}$} & Female & $11.90(4.3)$ & 12 & 25 & 6 \\
\hline & Male & $11.72(3.91)$ & 11.52 & 21 & 5 \\
\hline & Total & $11.84(4.15)$ & 12 & 25 & 5 \\
\hline \multirow{3}{*}{$\begin{array}{l}\text { Verbal fluency } \\
\text { (Animal) }\end{array}$} & Female & $24(5.4)$ & 25.50 & 39 & 15 \\
\hline & Male & $24.11(5.2)$ & 23 & 37 & 14 \\
\hline & Total & $24.10(3.5)$ & 23.50 & 39 & 14 \\
\hline \multirow{3}{*}{$\begin{array}{l}\text { Verbal fluency } \\
\text { (Fruit) }\end{array}$} & Female & $19.40(3.60)$ & 19 & 29 & 13 \\
\hline & Male & $17.91(3.60)$ & 18 & 24 & 11 \\
\hline & Total & $18.81(3.60)$ & 19 & 29 & 11 \\
\hline \multirow{3}{*}{$\begin{array}{l}\text { Verbal fluency } \\
\text { (Verb) }\end{array}$} & Female & $17.20(5.90)$ & 16 & 29 & 7 \\
\hline & Male & $18.30(5.20)$ & 19 & 27 & 10 \\
\hline & Total & $17.60(5.60)$ & 17 & 29 & 7 \\
\hline
\end{tabular}

JMR

And the lowest correlation coefficient is in semantic verbal fluency and phonological verbal fluency tasks are related to fruits and /A/. All subtests have a significant correlation with one of the tasks of verbal fluency test while subtest 3 (GO/NO-GO) has no significant correlation with verbal fluency tasks.

The results also support a significant correlation between the verbal fluency and language part of the MMSE test with the semantic verbal fluency $(\mathrm{P}=0.000)$. However, there is no significant correlation between MMSE total score and the verbal fluency. Based on all the data results, no significant correlations were found between the IFS-P total score and MMSE test but there is a significant correlation between IFS-P with verbal fluency tasks.

In order to compare the grades of the 3 tests, we converted all scores to the standard score in the graph, then the scores of one of the participants are standardized and shown in the profile form (Figure 1). The IFS-P score and MMSE are shown in Figure 2 and the IFS-P score and verbal fluency scores are shown in Figure 3. We used the scatter chart to better illustrate the data (because in these graphs each point represents one person's data), as what participant scored in which three tests.

Table 3. Spearman correlation coefficient $(\mathrm{P})$ between IFS-P and MMSE

\begin{tabular}{cccc}
\hline IFS & MMSE (Total) & MMSE (Cognitive Part) & MMSE (Language Part) \\
\hline IFS (Total) & $0.20(0.15)$ & $0.14(0.32)$ & $0.17(0.23)$ \\
\hline IFS-P1 & $0.30(0.00)$ & $0.30(0.00)$ & $0.15(0.20)$ \\
\hline IFS-P2 & $0.31(0.02)$ & $0.32(0.01)$ & $0.14(0.33)$ \\
\hline IFS-P3 & $0.08(0.55)$ & $0.06(0.64)$ & $-0.02(0.84)$ \\
\hline IFS-P4 & $0.30(0.05)$ & $0.19(0.18)$ & $0.27(0.03)$ \\
\hline IFS-P5 & $0.34(0.01)$ & $0.32(0.02)$ & $0.18(0.19)$ \\
IFS-P6 & $0.06(0.66)$ & $0.013(0.92)$ & $0.08(0.56)$ \\
IFS-P7 & $0.015(0.92)$ & $0.019(0.89)$ & $-0.12(0.38)$ \\
\hline IFS-P8 & $0.051(0.72)$ & $0.003(0.98)$ & $0.22(0.10)$ \\
\hline
\end{tabular}


Table 4. Spearman correlation coefficient (P value) between IFS-P and verbal fluency

\begin{tabular}{ccccccc}
\hline IFS & $\begin{array}{c}\text { Verbal Fluency } \\
\text { /F/ }\end{array}$ & $\begin{array}{c}\text { Verbal Fluency } \\
\text { /S/ }\end{array}$ & $\begin{array}{c}\text { Verbal } \\
\text { Fluency /A/ }\end{array}$ & $\begin{array}{c}\text { Semantic Fluency } \\
\text { (Animal) }\end{array}$ & $\begin{array}{c}\text { Semantic } \\
\text { Fluency (Fruit) }\end{array}$ & $\begin{array}{c}\text { Semantic } \\
\text { Fluency (Verb) }\end{array}$ \\
\hline $\begin{array}{c}\text { IFS } \\
\text { (Total) }\end{array}$ & $0.36(0.01)$ & $0.44(0.00)$ & $0.35(0.01)$ & $0.38(0.00)$ & $0.30(0.03)$ & $0.56(0.00)$ \\
IFS-P1 & $0.21(0.12)$ & $0.40(0.00)$ & $0.23(0.06)$ & $0.24(0.08)$ & $0.08(0.56)$ & $0.21(0.12)$ \\
IFS-P2 & $0.22(0.12)$ & $0.45(0.00)$ & $0.26(0.07)$ & $0.24(0.00)$ & $0.08(0.56)$ & $0.22(0.12)$ \\
\hline IFS-P3 & $0.01(0.93)$ & $0.037(0.79)$ & $0.56(0.70)$ & $0.10(0.47)$ & $0.054(0.71)$ & $0.90(0.53)$ \\
\hline IFS-P4 & $0.32(0.02)$ & $0.33(0.01)$ & $0.34(0.01)$ & $0.29(0.03)$ & $0.26(0.06)$ & $0.41(0.00)$ \\
IFS-P5 & $0.25(0.07)$ & $0.24(0.08)$ & $0.21(0.13)$ & $0.067(0.64)$ & $0.22(0.11)$ & $0.28(0.04)$ \\
IFS-P6 & $0.09(0.53)$ & $0.31(0.02)$ & $0.12(0.39)$ & $0.22(0.11)$ & $0.05(0.68)$ & $0.21(0.13)$ \\
IFS-P7 & $0.32(0.02)$ & $0.27(0.05)$ & $0.32(0.02)$ & $0.27(0.05)$ & $0.02(0.86)$ & $0.29(0.03)$ \\
IFS-P8 & $0.59(0.00)$ & $0.26(0.06)$ & $0.28(0.04)$ & $0.33(0.01)$ & $0.39(0.00)$ & $0.50(0.00)$ \\
\hline
\end{tabular}

Note: Significance level $\mathrm{P}<0.05$

Table 5. Spearman correlation coefficient $(\mathrm{P})$ between MMSE and verbal fluency

\begin{tabular}{ccccccc}
\hline MMSE & $\begin{array}{c}\text { Verbal } \\
\text { Fluency/F/ }\end{array}$ & $\begin{array}{c}\text { Verbal Fluency } \\
\text { /S/ }\end{array}$ & $\begin{array}{c}\text { Verbal Fluency } \\
\text { /A/ }\end{array}$ & $\begin{array}{c}\text { Semantic } \\
\text { Fluency } \\
\text { (Animal) }\end{array}$ & $\begin{array}{c}\text { Semantic } \\
\text { Fluency } \\
\text { (Fruit) }\end{array}$ & $\begin{array}{c}\text { Semantic } \\
\text { Fluency (Verb) }\end{array}$ \\
\hline MMSE (Total) & $0.19(0.16)$ & $0.17(0.23)$ & $0.07(0.60)$ & $0.04(0.76)$ & $0.22(0.11)$ & $0.14(0.31)$ \\
\hline $\begin{array}{c}\text { MMSE (cognitive } \\
\text { part) }\end{array}$ & $0.23(0.10)$ & $0.15(0.27)$ & $0.02(0.85)$ & $0.08(0.58)$ & $0.12(0.38)$ & $0.005(0.97)$ \\
\hline $\begin{array}{c}\text { MMSE (language } \\
\text { part) }\end{array}$ & $0.06(0.67)$ & $0.15(0.30)$ & $0.04(0.74)$ & $0.05(0.70)$ & $0.42(0.00)$ & $0.46(0.00)$ \\
\hline
\end{tabular}

Note: Significance level $\mathrm{P}<0.05$

JMR

\section{Discussion}

In this study, IFS-P showed no correlation with cognitive tests such as MMSE while it correlated with executive function tests such as verbal fluency tasks. There is no association between IFS-P total scores and the MMSE total score; however, there is some association between IFS-P total scores and verbal fluency tasks in healthy people. In other studies, including the study on the adaptation of the Chilean version of the IFS test, the correlation of this test with other tests, including the verbal fluency test (phonological verbal fluency of /A/ and $/ \mathrm{P} /$ and semantic verbal fluency of animals), FAB test, cognitive tests such as MMSE and Addenboorke's Cog-

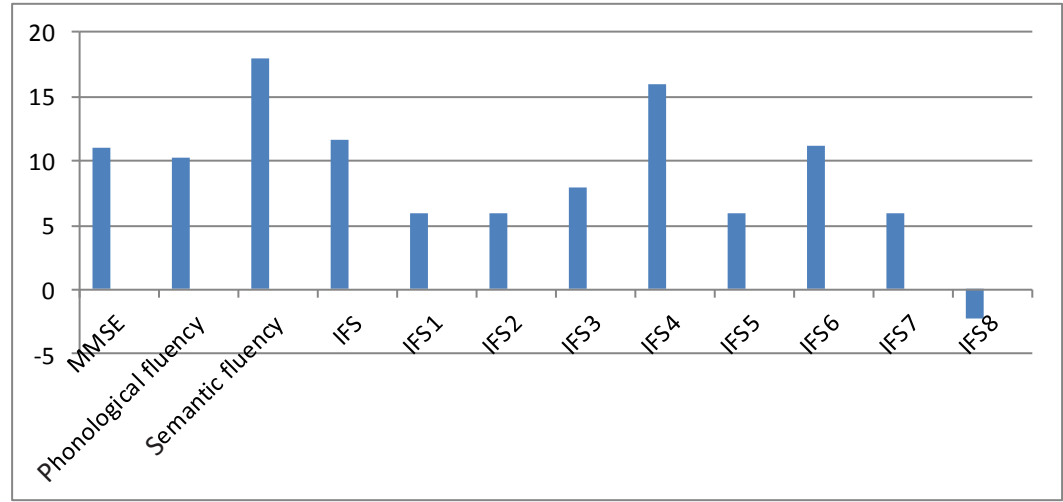

Figure 1. Standard score of one participant 


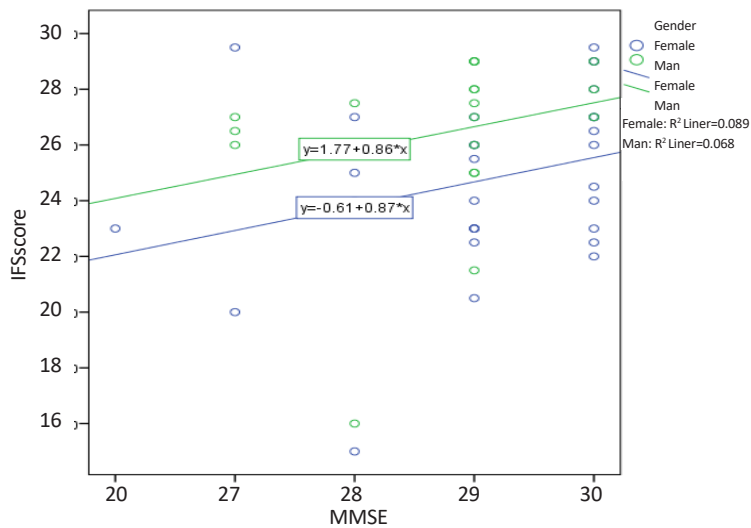

Figure 2. IFS-P and MMSE scores in scatter chart

nitive Examination (ACE) were assessed and reported in the patients with dementia. The coefficient of correlation of IFS-Ch version with semantic verbal fluency of animals was 0.72 , with phonological verbal fluency of /A/0.68 and of /P/0.78, and with MMSE test 0.87 in the patients with dementia [2].

As mentioned before, in IFS-Ch, there was a relationship between IFS-Ch and other tests in patients with dementia. IFS-Ch showed good correlation with other measures of executive functions such as phonological verbal fluency with letters A and P, semantic verbal fluency of animals and the FAB, global cognitive efficiency (Addenbrook's cognitive examination-revised [ACERCh] and MMSE), dysexecutive symptoms, dementia severity, and impairment activities of daily living [7] in patients with dementia. Also, significant correlations were found between IFS-Ch with animal verbal fluency $(\mathrm{r}=0.728, \mathrm{P}<0.05)$; /A/ verbal fluency $(\mathrm{r}=0.681, \mathrm{P}<0.05)$; $/ \mathrm{P} /$ verbal fluency $(\mathrm{r}=0.783, \mathrm{P}<0.05)$, and $\mathrm{MMSE}$ $(\mathrm{r}=0.874, \mathrm{P}<0.05)$ in patients with dementia [2]

In original version of IFS, the IFS total score also correlated with classical executive tests such as verbal fluency, Wisconsin Card Sorting Test (WCST), TMT-B (Trail Making Test, part B) and cognitive tests such as MMSE and ACE. In Torralva et al. study, no significant correlation was observed between IFS total score and MMSE in the control group of original version of IFS [1]. The original version of the IFS test had greater corre-
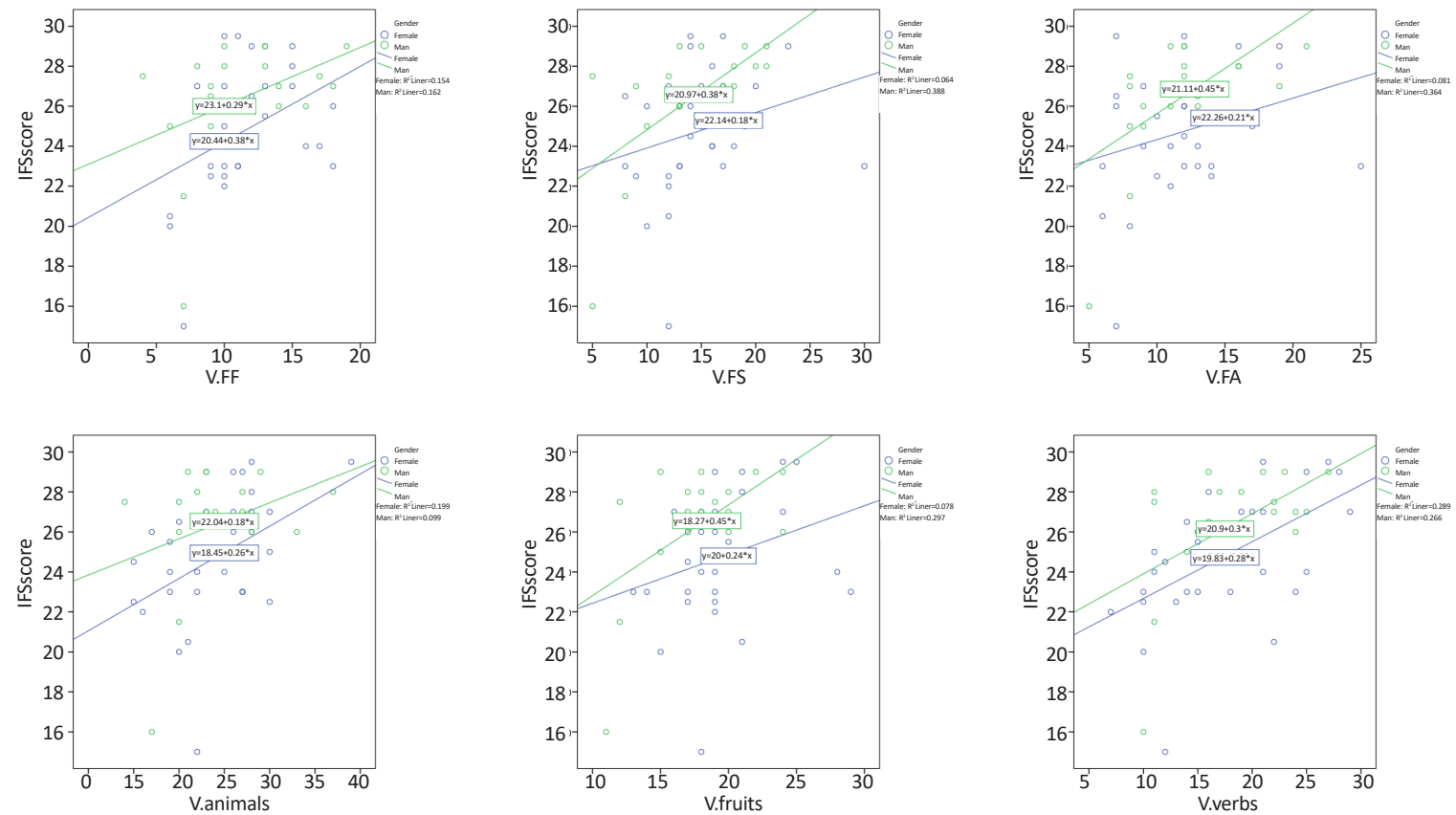

Figure 3. IFS-P and verbal fluency scores in scatter chart

Note: V.FF: Verbal Fluency/f/; V.FS: Verbal Fluency/s/, V.FA: Verbal Fluency/a/ 
lation with other executive function tests such as verbal fluency test. The correlation coefficient values of IFS test were 0.67 and 0.77 with phonological verbal fluency and semantic verbal fluency, respectively. Also, the IFS test correlates with other cognitive tests such as MMSE and ACE. The correlation coefficient reported in the Alzheimer group with the MMSE test was 0.57 and with the ACE test as 0.55, while the correlation coefficient in healthy people for MMSE and ACE tests were 0.40 and 0.55 , respectively.

According to Torraleva et al. study, there is a significant correlation between IFS and verbal fluency test $(r=0.67$, $\mathrm{P}<0.001$ ). In this study, the correlation coefficient between IFS and MMSE is poorly reported in healthy people. The correlation coefficient in a healthy group is equal to $0.40(\mathrm{P}=0.04)$ [1]. In this study, no significant correlation was found between IFS-P and MMSE but IFS-P has correlation with verbal fluency. And all participants have good score in MMSE but their score were worse in IFS-P. Therefore, in similar studies such as Torrallova et al. IFS-P has correlation with other executive tests and no correlation with cognitive tests. According to IFS-P subtests, this test can evaluate cognitive and linguistic issues, also it can examine all parts of the executive functions, so it can provide more accurate and practical results. Subtests are discussed in more detail in this section.

Two subtests of total IFS-P are language-related; the proverb interpretation (IFS-P7) and verbal inhibitory control (IFS-P8). The lowest score belongs to the linguistic sections especially to the verbal inhibitory control section. This reflects the impact of the language on the performance of individuals and that the score is dependent on language and culture. Therefore, there is a logical connection between IFS and cognitive tests in individuals with dementia. It seems that in Persian, more people with different educational background and age groups should be studied, also these tests should be administered to patients with cognitive impairments so that their results can enhance the findings of this study.

According to the results, older age decreases IFS-P score while high educational level increases IFS-P score, thus the IFS-P score relates to age and education of participants and these variables can affect the total score. This study showed that these three tests are not correlated completely and cannot replace each other. It is suggested that in the clinical settings, all three tests be used together to evaluate the subjects.

\section{Ethical Considerations}

\section{Compliance with ethical guidelines}

This study has been approved by the Ethics Committee of Tehran University of Medical Sciences (Code: IR.TUMS.FNM.REC.1396.2692).

\section{Funding}

This study was funded by the School of Rehabilitation of Tehran University of Medical Sciences (Grant for fatemeh satarian's master thesis).

\section{Conflict of interest}

The authors declare no conflict of interest.

\section{Acknowledgments}

We would like to thank all study participants for their cooperation.

\section{References}

[1] Torralva T, Roca M, Gleichgerrcht E, Lopez P, Manes F. INECO Frontal Screening (IFS): A brief, sensitive, and specific tool to assess executive functions in dementia-corrected version. Journal of the International Neuropsychological Society. 2009; 15(5):777-86. [DOI:10.1017/S1355617709990415] [PMID]

[2] Ihnen J, Antivilo A, Muoz Neira C, Slachevsky A. [Chilean version of the INECO Frontal Screening (IFS-Ch): Psychometric properties and diagnostic accuracy (Spanish)]. Dementia \& Neuropsychologia. 2013; 7(1):40-7. [DOI:10.1590/S198057642013DN70100007] [PMID] [PMCID]

[3] Satarian F, Mehri A, Jalali Sh. Validity and reliability of INECO Frontal Screening (IFS) in Persian dementia patients. (In press).

[4] Wanda W, Adler R, Love R. Neurology for the speech-language pathologist. Virginia: Elsevier Health Sciences; 2008.

[5] Marshall GA, Rentz DM, Frey MT, Locascio JJ, Johnson KA, Sperling RA, et al. Executive function and instrumental activities of daily living in mild cognitive impairment and Alzheimer's disease. Alzheimer's \& Dementia. 2011; 7(3):300-8. [DOI:10.1016/j.jalz.2010.04.005] [PMID] [PMCID]

[6] Baudic S, Dalla Barba G, Thibaudet MC, Smagghe A, Remy P, Traykov L. Executive function deficits in early Alzheimer's disease and their relations with episodic memory. Archives of Clinical Neuropsychology. 2006; 21(1):15-21. [DOI:10.1016/j. acn.2005.07.002] [PMID]

[7] Royall DR, Lauterbach EC, Cummings JL, Reeve A, Rummans TA, Kaufer DI, et al. Executive control function: A review of its promise and challenges for clinical research. A report from the committee on research of the american neu- 
ropsychiatric association. The Journal of Neuropsychiatry and Clinical Neurosciences. 2002; 14(4):377-405. [DOI:10.1176/ jnp.14.4.377] [PMID]

[8] Chan RC, Shum D, Toulopoulou T, Chen EY. Assessment of executive functions: Review of instruments and identification of critical issues. Archives of Clinical Neuropsychology. 2008; 23(2):201-16. [DOI:10.1016/j.acn.2007.08.010] [PMID]

[9] Crawford JR. Introduction to the assessment of attention and executive functioning. Neuropsychological Rehabilitation. 1998; 8(3):209-11. [DOI:10.1080/713755574]

[10] Satarian F, Ghoreishi Z, Jalaei S. A review of common and quick tests in executive function in adults with neurological disorder. Advances in Biosciences \& Clinical Medicine. 2017; 25. [DOI:10.7575/aiac.abcmed.ca1.25]

[11] Ansari NN, Naghdi S, Hasson S, Valizadeh L, Jalaie S. Validation of a Mini-Mental State Examination (MMSE) for the Persian population: A pilot study. Applied Neuropsychology. 2010; 17(3):190-5. [DOI:10.1080/09084282.2010.499 773] [PMID]

[12] Tombaugh TN, Kozak J, Rees L. Normative data stratified by age and education for two measures of verbal fluency: FAS and animal naming. Archives of Clinical Neuropsychology. 1999; 14(2):167-77. [DOI:10.1093/arclin/14.2.167] 
